\title{
INICIATIVAS DE DIVERSIFICAÇÃO AO CULTIVO DO TABACO NO MUNICÍPIO DE SANTA CRUZ DO SUL - RS: UM ESTUDO DE CASO
}

\author{
Rosiéle Cristiane Ludtke ${ }^{1}$ \\ Anelise Graciele Rambo ${ }^{2}$ \\ Janete Stoffel ${ }^{3}$
}

\section{RESUMO}

Este artigo analisa os mecanismos que levam famílias produtoras de tabaco a implementarem iniciativas de diversificação e analisar a dinâmica destas mudanças no município de Santa Cruz do Sul/RS. Pretende-se verificar motivações e alternativas de diversificação da produção na maior região produtora de tabaco do país, e quais políticas públicas são mobilizadas. Para tal, será feita uma análise considerando os reflexos da modernização da agricultura, em especial, sobre a agricultura camponesa, considerando aspectos sociais, econômicos e ambientais. O referencial teórico mobilizado engloba a sociedade de risco de Ulrich Beck e a perspectiva orientada ao ator de Long e Ploeg. Enquanto resultados, verifica-se que as iniciativas de diversificação manifestam uma autoconfrontação aos riscos produzidos pela monocultura do tabaco a qual está pautada nos ditames da Revolução Verde. Essa produção diversificada tende a fortalecer a capacidade de agência dos camponeses, como resposta aos riscos produzidos pela cadeia produtiva do tabaco e emerge de uma perspectiva onde o sujeito camponês, de acordo com sua realidade, seu modo de vida, busca minimizar estes efeitos.

Palavras-chave: Camponeses, Autoconfrontação, Diversificação, Tabaco.

\section{INITIATIVES TOBACCO CULTIVATION DIVERSIFICATION IN THE CITY OF SANTA CRUZ DO SUL - RS: A CASE STUDY}

\begin{abstract}
This article analyzes the mechanisms by which tobacco farming families to implement diversification initiatives and analyze the dynamics of these changes in Santa Cruz do Sul/RS. It is intended to verify motivations and production diversification alternatives in most tobacco producing region of the country, and what public policies are mobilized. This requires an analysis will be done considering negative effects of agricultural modernization, in particular on peasant agriculture,

${ }^{1}$ Graduada em Tecnologia em Agropecuária (UERGS). Especialização no Programa de Formação para Docentes (UERGS). Mestre em Agroecologia e Desenvolvimento Rural (UFFS/Laranjeiras do Sul - PR). Email: rosieleludtke@gmail.com

${ }^{2}$ Graduada em Geografia (UNIJUì), Mestre em Geografia (UFRGS). Doutora em Desenvolvimento Rural (UFRGS). Professora do Departamento Interdisciplinar (UFRGS). Email: ane_rambo@yahoo.com.br

${ }^{3}$ Graduada em Ciências Econômicas (UNIJUI). Mestre em Desenvolvimento Regional (UNIJUI). Doutora em Desenvolvimento Regional (UNISC). Professora Adjunta (UFFS). Email: janete.stoffel@gmail.com
\end{abstract}


considering social, economic and environmental. The theoretical framework encompasses mobilized the risk society Ulrich Beck and the prospect oriented actor Long and Ploeg. As results, it appears that diversification initiatives manifest a selfconfrontation to the risks produced by the tobacco monoculture which is guided in the dictates of the Green Revolution. This diversified production tends to strengthen the agency's capacity of farmers in response to the risks produced by this production chain and emerge from a perspective where the individual peasant, according to their reality, their way of life, seeks to minimize these effects.

Keywords: Diversification, Tobacco, Peasants, Self- confrontation.

\section{INTRODUÇÃO}

O estudo de iniciativas de diversificação em áreas produtoras de tabaco no município de Santa Cruz do Sul é instigado pelas seguintes inquietações: se o cultivo do tabaco é uma das atividades mais rentáveis por área plantada, porque as famílias fumicultoras não se mantêm no monocultivo do tabaco? O que faz com que, cada vez mais famílias realizem processos de diversificação? Se é tão rentável, por que os jovens fumicultores também saem das propriedades e buscam alternativas nas cidades?

Frente a esses questionamentos, o presente estudo de caso busca investigar o que leva famílias de camponeses ${ }^{4}$ a implementarem iniciativas de diversificação ao cultivo do tabaco e encontrar alternativas de renda na maior região produtora de tabaco do país. Entendemos que essas iniciativas de diversificação são decorrentes do que Ulrich Beck (1995) chama de sociedade de risco. Ou seja, entendemos que as iniciativas de diversificação desencadeadas pelos camponeses junto a suas organizações representativas e, com o auxílio de políticas públicas, podem ser compreendidas enquanto autoconfrontação com os efeitos colaterais da modernização da agricultura e da consequente, monocultura do tabaco ${ }^{5}$.

Por iniciativas de diversificação compreendemos o processo social e econômico de criação da diversidade dos meios de vida. Já a diversidade é entendida como uma condição que se realiza segundo diferentes formas de renda,

\footnotetext{
${ }^{4}$ Utilizaremos o termo camponês ao invés de agricultor familiar pela afinidade que temos com o conceito e por entender que o termo historicamente utilizado foi camponês. Entendemos que agricultor familiar é um termo utilizado a partir do surgimento do Pronaf na década de 1990 e serve para reforçar o modelo moderno de agricultura, baseado na especialização produtiva e no produtivismo. Portanto, são os camponeses que, no decorrer da história, sempre mantiveram um jeito de ser e de viver próprios e cujo objetivo principal é a manutenção da família, garantindo a produção diversificada de alimentos como uma das suas formas de sobrevivência (CARVALHO, 2012).

${ }^{5}$ Consideramos o sistema de integração da cadeia produtiva de tabaco uma monocultura intensiva (e não necessariamente extensiva) devido ao fato desta ser a principal e, não raro, a única fonte de renda das famílias envolvidas em seu cultivo. Em estudo de Rambo et al. (2013), no município de Arroio do Tigre/RS, numa amostra de 38 famílias foi verificado que $13 \%$ delas caracterizavam-se como diversificadas, $26 \%$ pouco diversificadas e $61 \%$ especializadas. Estudo idêntico foi realizado por Sartorelli e Rambo (2014) no município de Laranjeiras do Sul/PR. O estudo evidenciou um grau de diversificação maior dos fumicultores, se comparado a Arroio do Tigre, devido à introdução mais recente deste cultivo nas propriedades, por não ser a atividade que mais gera renda e, ainda, por ser predominantemente tabaco tipo burley, o qual demanda menos trabalho. Para esta categorização, os autores levaram em consideração a renda gerada pelo tabaco e o tempo dedicado pela família ao seu cultivo. Já Freitas (2015), em estudo com 250 famílias fumicultoras de 13 municípios do Vale do Rio Pardo/RS, verificou que apenas $16 \%$ das famílias eram diversificadas, $43 \%$ quase diversificadas, $28 \%$ pouco diversificadas e $14 \%$ especializadas. Para tal tipologia, foram levadas em consideração 9 variáveis (área produtiva, insumos químicos, lenha, renda do tabaco, custeio com produção de tabaco, tempo de trabalho no tabaco, tempo dedicado às demais atividades, perspectivas caso não plantasse fumo).
} 
atividades, ocupações, sistemas de produção, estrutura fundiária. A diversidade manifesta-se por meio de um repertório de iniciativas que funcionam e operam como alternativas em contexto de privação e dificuldades, muitas vezes decorrentes da falta de opções, mas também em decorrência dos equívocos provocados pela especialização (SCHNEIDER, 2010). Ploeg (2008) ressalta que a diversificação implica na luta constate, por parte dos agricultores, pelo fortalecimento da base de recursos disponíveis e de sua capacidade de luta constante por autonomia e liberdade. Seria a capacidade de criação de espaço de manobra pelos agricultores que inovam e reagem em face do contexto de hostilidade, privação e adversidade.

No mesmo sentido, Freitas (2015, p. 112) afirma que:

\begin{abstract}
Diversificar significa ter menor dependência de fatores externos, menor dependência de recursos controlados por atores externos e utilizar ao máximo as atividades dentro e fora da unidade produtiva, agrícolas ou não agrícolas, procurando, ao fim, a melhoria dos meios de vida e consequentemente das condições de vida. A diversificação torna-se um fator-chave no desenvolvimento, pois dá aos atores sociais a possibilidade de ter maior autonomia e construir trajetórias de vida consideradas significativas.
\end{abstract}

No contexto da sociedade de risco, entendemos que iniciativas de diversificação, que buscam maior autonomia e liberdade emergem em contraponto ao modelo vigente, de modo a dar respostas pela autoconfrontração dos camponeses aos riscos produzidos pela própria modernidade. No caso em estudo, entendemos que as iniciativas de diversificação $0^{6}$, ou seja, aquelas iniciativas que funcionam e operam como alternativas em contexto de privação e dificuldades, são uma autoconfrontação aos riscos produzidos pela monocultura do tabaco a qual está pautada nos moldes da Revolução Verde. Além disso, a diversificação pode fortalecer a capacidade de agência dos agricultores, contribuindo com o processo de desenvolvimento rural. Para analisar essa capacidade de agência, nos valeremos da Perspectiva Orientada ao Ator (POA) de Norman Long (2007) e Jan Douwe Van Der Ploeg (2008). Essa abordagem ressalta a capacidade dos atores desenvolverem iniciativas de diversificação no sentido de buscar alternativa à produção hegemônica do tabaco, levando em conta a realidade local, vinculada à cultura, ao modo de ser e de viver dos camponeses, fortalecendo sua capacidade de agência na condução e promoção do desenvolvimento, num processo marcado por diversas formas de resistência e busca por autonomia.

Frente ao mencionado, procura-se estudar a realidade do município de Santa Cruz do Sul, local onde está instalado o maior complexo agroindustrial de beneficiamento do tabaco no mundo, mas também onde estão sendo realizadas iniciativas de diversificação a este cultivo. Buscamos evidenciar, frente aos estilos de agricultura historicamente constituídos, formas alternativas e características que possam ser potencializadas enquanto alternativas de desenvolvimento rural.

Considera-se que os camponeses ao se autoconfrontarem, tanto com os efeitos colaterais da modernização da agricultura, quanto com os riscos sistêmicos decorrentes na questão ambiental, social e econômica, buscam implementar iniciativas distintas para diversificar sua produção e com isso ampliar as fontes de renda e reduzir a dependência à cadeia produtiva do tabaco. Para tanto, o objetivo

\footnotetext{
${ }^{6}$ As indústrias fumageiras também incentivam a diversificação produtiva, mas há que se ressaltar que este fato não muda a relação subalterna por parte dos fumicultores com a indústria, ou seja, não gera autonomia para as famílias.
} 
geral da pesquisa consiste em verificar quais mecanismos levam famílias produtoras de tabaco a implementarem iniciativas de diversificação e analisar a dinâmica destas mudanças no município de Santa Cruz do Sul/RS. Procura-se entender o caminho percorrido por essas famílias no sentido de buscar alternativas de diversificação ao tabaco. Ademais, busca-se caracterizar a cadeia produtiva do tabaco, abordando aspectos sociais, ambientais e econômicos existentes no município em estudo e apontar os atores envolvidos nas iniciativas, destacando seu papel no desenvolvimento do processo. Além disto, identificar as motivações e caracterizar a trajetória das iniciativas empregadas pelas famílias camponesas para a diversificação do tabaco e, analisar quais políticas públicas são mobilizadas nas iniciativas, são objetivos específicos que pretendemos perseguir.

O presente artigo está estruturado em cinco seções, além desta introdução. $\mathrm{Na}$ segunda está a discussão sobre a modernização da agricultura e a cadeia produtiva do tabaco. A terceira seção é composta pelo referencial teórico à luz das contribuições de Ulrich Beck (1995) que nos ajuda a compreender o conceito da sociedade de risco. A Perspectiva Orientada ao Ator de Long (2007) e Ploeg (2008) nos auxilia a compreender como ocorre a reação/adaptação aos problemas gerados pela moderna agricultura. $\mathrm{Na}$ quarta seção, inicialmente, é apresentada a metodologia do estudo, e na sequencia, estão as iniciativas de diversificação das propriedades alvo desta pesquisa, que relacionam o objeto empírico com a base teórica relacionando autoconfrontação e capacidade de agência. Por último, na quinta seção encontram-se as considerações finais do estudo em questão.

\section{A MODERNIZAÇÃO DA AGRICULTURA E A CADEIA PRODUTIVA DO TABACO}

A história da agricultura é marcada por conflitos e mudanças ao longo dos anos. No Brasil, até meados do século XX, a maioria das pessoas residia no campo, sendo este caracterizado pela produção diversificada e tendo como principal objetivo o autoconsumo. Depois da Segunda Guerra Mundial começam a ocorrer mudanças profundas na agricultura do mundo todo, o que se deu por meio da implantação do projeto chamado "Revolução Verde". Para Zamberlan (2012, p. 26), "a Revolução Verde é a penetração capitalista no campo. Tem como objetivo a maximização produtiva que objetivamente usa a natureza para conseguir sempre mais lucros, sem se preocupar com os efeitos da tecnologia empregada sobre o meio ambiente circundante".

Essas mudanças chegaram ao Brasil a partir de 1960, iniciando o processo da "modernização conservadora" da agricultura brasileira. A Revolução Verde representou investimentos massivos em três áreas da ciência: agroquímica, motomecanização e manipulação genética (ZAMBERLAN, 2012). Seus objetivos consistiam na introdução da mecanização agrícola, dos insumos químicos (venenos e fertilizantes), dos medicamentos veterinários, das sementes geneticamente melhoradas e a disseminação das monoculturas. Além disto, a Revolução Verde incentivou o uso de crédito na agricultura, facilitando a adoção deste pacote tecnológico a partir de mecanismos de seguro de preço e seguro de crédito à produção, da pesquisa e da assistência técnica difusionista (DELGADO, 2012).

Essas mudanças impactaram significativamente no modo de viver, de ser, e de fazer a agricultura. $O$ modo camponês, que provia primeiramente a produção de

\footnotetext{
${ }^{7}$ Segundo Guimarães (1977, p. 3), a estratégia de modernização conservadora, diferentemente da reforma agrária, tem por objetivo o crescimento da produção agropecuária mediante a renovação tecnológica, sem que seja tocada ou grandemente alterada a estrutura agrária.
} 
alimentos e cujo foco principal era a reprodução social da família, foi sendo substituído, aos poucos, pela chamada agricultura moderna (GORGEN, 2004).

Neste moderno modelo de agricultura, está inserida a monocultura do tabaco (Solanunn tabaco). A cadeia produtiva do tabaco no Sul do Brasil está estruturada sob o sistema de integração entre indústrias e fumicultores, pela qual os camponeses estão subordinados e tem pouca autonomia. Este modelo produtivo é marcado por muitas contradições. Os lucros das empresas fumageiras escondem a realidade que vivem famílias produtoras do tabaco (ETGES, 2005). As empresas exercem domínio sobre as famílias que se submetem as regras impostas, ou se satisfazem pelos "benefícios" de receber os insumos e só pagar após a colheita com a produção. Este sistema é adotado pelo conjunto das empresas fumageiras, ofertando os insumos (sementes, fertilizantes, venenos) como adiantamento, além do financiamento da construção das estufas (DESER, 2003). Prevê ainda assistência técnica aos camponeses que, em contrapartida, garantem a venda integral e exclusiva da produção à integradora. Observa-se que a assistência técnica oferecida é unicamente direcionada para o cultivo do fumo, de forma a atender os interesses das indústrias fumageiras (ALMEIDA, 2005).

O sistema de integração caracteriza um contrato de adesão realizado entre as empresas fumageiras e o camponês, cujas obrigações das partes estão descritas no quadro a seguir:

Quadro 1 - Características do sistema de integração

\begin{tabular}{|l|l|}
\hline Compromissos/obrigações da fumageira & Compromissos/obrigações do camponês \\
\hline $\begin{array}{l}\text { Concessão de crédito aos camponeses para } \\
\text { que adquiram os materiais e estruturas } \\
\text { necessários para a produção do fumo em } \\
\text { folha. }\end{array}$ & $\begin{array}{l}\text { Utilização do crédito, materiais e estruturas } \\
\text { exclusivamente para a produção de tabaco. }\end{array}$ \\
\hline $\begin{array}{l}\text { Fornecimento dos insumos necessários ao } \\
\text { plantio do tabaco. }\end{array}$ & Plantar, cuidar, colher e classificar o tabaco. \\
\hline $\begin{array}{l}\text { Acompanhamento técnico de um instrutor } \\
\text { agrícola exclusivamente para o plantio do } \\
\text { tabaco. }\end{array}$ & $\begin{array}{l}\text { Seguir rigorosamente as recomendações do } \\
\text { técnico. }\end{array}$ \\
\hline $\begin{array}{l}\text { Compra garantida de toda a produção do } \\
\text { camponês. }\end{array}$ & $\begin{array}{l}\text { Comercializar a totalidade da produção } \\
\text { dentro da estimativa prevista para a } \\
\text { fumageira. }\end{array}$ \\
\hline
\end{tabular}

Fonte: Almeida (2005). Organização própria.

Atualmente são 182.970 famílias fumicultoras no Brasil, sendo a maior parte delas de pequenos proprietários e sem terra. O cultivo do tabaco fixou-se na região sul do país, em áreas de topografia acidentada. A área média das propriedades dos fumicultores é de 15,7 ha, sendo, normalmente, apenas 2,64 ha utilizados para o cultivo de fumo (ANUÁRIO BRASILEIRO DO TABACO, 2014). Embora constitua-se numa importante fonte de renda para milhares de famílias da região Sul do Brasil, há diversos problemas relacionados ao cultivo do tabaco. Pode-se citar: tabagismo, uso de venenos que causa diversos impactos ambientais, empobrecimento das famílias, penosidade do trabalho, doenças associadas à atividade produtiva e ao uso dos venenos, a doença da folha verde, elevado índice de suicídios decorrentes de frustrações na produção e intoxicações (DESER, 2003).

Para Almeida (2005), a renda das famílias envolvidas no cultivo de tabaco, de fato, não lhes confere grande autonomia financeira, além de exigir muita mão de obra durante sua safra. Há um atrelamento destas famílias à indústria fumageira pelo fato de que esta lhes confere a "garantia de mercado". Esse atrelamento 
constitui-se como um fator determinante e gera dependência das famílias à indústria fumageira.

Segundo Etges (2005), todos estes insumos fornecidos, a priori, às famílias como adiantamento na safra, caracterizam um negócio lucrativo às empresas fumageiras, pois fornecem estes insumos a preço de mercado. Como realizam compra destes em grande quantidade, conseguem negociar a um preço mais barato. As aplicações de venenos são feitas de maneira preventiva, ou seja, antes mesmo de aparecer uma praga ou doença. Ademais, a disponibilização antecipada do pacote agroquímico pelas fumageiras aos camponeses constitui-se numa considerável fonte de lucro para as empresas do setor (ETGES, 2005).

De acordo com Pinheiro e Luz (1998, p. 155)

As fumageiras, hoje, não precisam obrigar o produtor a absorver insumos, optar por seguro ou construções de investimento, pois o fumicultor já está irremediavelmente atrelado ao esquema e seus instrutores controlam a fidelidade. Os fumicultores reconhecem que estão intoxicados e com suas vidas e de seus filhos seriamente comprometidas. Também não acreditam que seja possível produzir sem esta relação opressiva, e nem sequer acreditam que existam alternativas. Submetem-se. E a ideologia do dominador passa a ser a visão do dominado. Infelizmente este é o auge da servidão.

Frente a isso, é possível questionar o tipo de desenvolvimento que o sistema integrado de produção de tabaco gera. Por um lado, há lucros significativos para as empresas fumageiras e números expressivos, em toneladas, de produção e de exportação, os quais se contrapõem à baixa qualidade de vida e a frágil situação econômica e social daqueles que plantam, cuidam, colhem e secam o tabaco. Estes, muitas vezes, pagam com a própria saúde e dos seus familiares e sofrem as consequências desse modelo de produção imposto pelas multinacionais do tabaco (ETGES, 2005).

Quanto à monocultura do tabaco, Schneider (2010a) enfatiza que as condições de produção do tabaco expõem os camponeses a situações paradoxais. De um lado, praticam uma atividade altamente rentável e lucrativa, que apesar de demandar uso intenso de mão de obra, pode ser realizada em pequenas áreas de terra, dado o volume total produzido por área plantada. A maximização do fator trabalho representa uma vantagem comparativa frente aos demais sistemas de cultivo ou criações, gerando uma competitividade incomum aos estabelecimentos de pequeno porte voltados à produção do tabaco. Por outro lado, esta produção gera uma situação de dependência e de vulnerabilidade, que fragiliza estas famílias e gera situações de pobreza e risco.

Segundo o Deser (2010), o faturamento total do setor fumageiro, exportação e consumo doméstico, em 2009 , foi de $R \$ 16,9$ bilhões. As exportações foram responsáveis por $87 \%$ e o consumo doméstico de cigarros representou $13 \%$. Deste total faturado na cadeia do fumo, os impostos e tributos arrecadados pelo governo absorveram $\mathrm{R} \$ 8,4$ bilhões (49\% do total); a indústria, $\mathrm{R} \$ 3,04$ bilhões (18\%); os fumicultores, $\mathrm{R} \$ 4,5$ bilhões $(26,8 \%)$ e a renda do comércio varejista correspondeu a $\mathrm{R} \$ 933$ milhões (5,5\%) do faturamento total (DESER, 2010).

No que se refere ao valor total ${ }^{8}$ faturado pela cadeia na safra $2014 / 2015$, a

\footnotetext{
${ }^{8}$ Valor total faturado corresponde ao valor resultante da multiplicação da quantidade vendida pelo preço. Ou seja, é o valor financeiro total que a cadeia gera, sem descontar os custos. Renda líquida é o valor que sobra depois de descontar todos os custos.
} 
parte do fumicultor representa a segunda menor, perdendo apenas para o comércio varejista.

Gráfico 1 - Distribuição da renda bruta do Setor Fumageiro

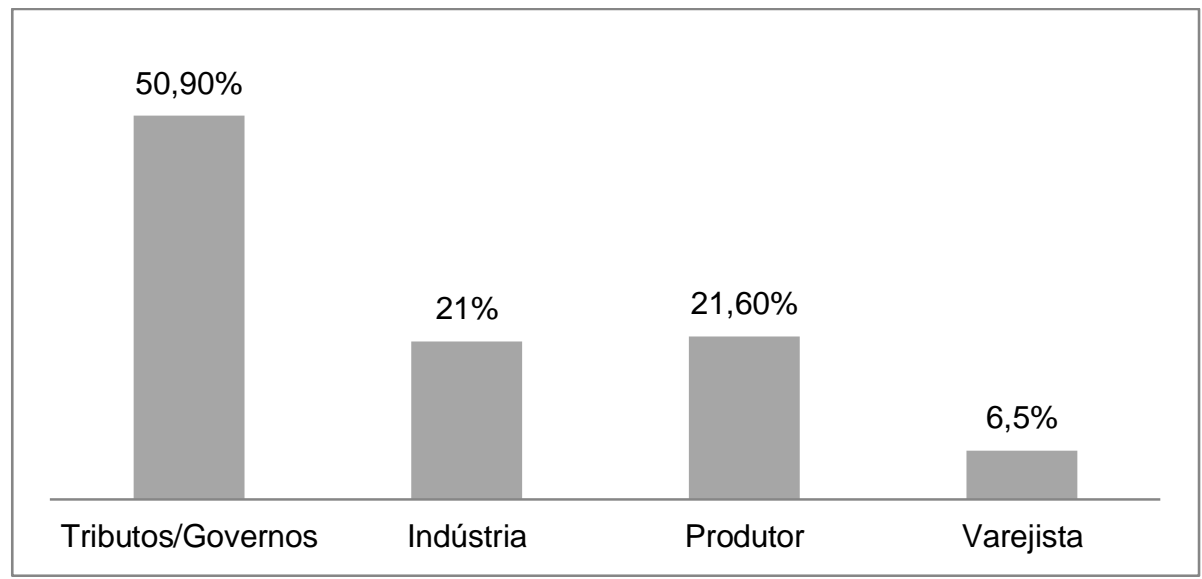

Fonte: Afubra (2014). Organização Própria.

No entanto, com relação à renda líquida, o produtor de tabaco é o que fica com a menor fatia da renda gerada, conforme demonstra o gráfico a seguir:

Gráfico 2 - Distribuição da renda líquida do Setor Fumageiro

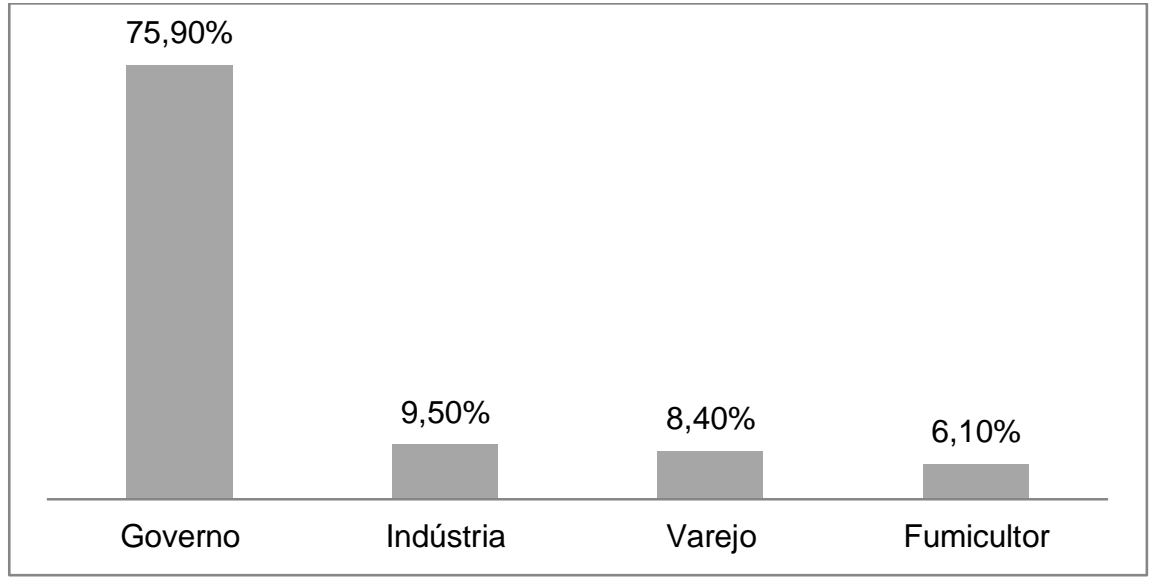

Fonte: DESER (2010). Organização própria.

Os resultados anuais de produção das safras demonstram que a cadeia produtiva do tabaco gera uma renda considerável. Na safra 2013/2014 foram produzidas no Brasil, 731.390 toneladas que, comercializadas, geraram um valor aproximado de $\mathrm{R} \$ 24$ bilhões de reais (ANUÁRIO BRASILEIRO DO TABACO, 2014). 
Cabe ressaltar a desigualdade na distribuição desta renda ao longo da cadeia produtiva, pois são as famílias que realizam todo trabalho de produção do tabaco, correndo riscos climáticos de intempéries do clima, riscos na saúde por possíveis intoxicações pelo efeito cumulativo do uso de agrotóxicos e da absorção da nicotina, bem como de doenças funcionais pelo trabalho pesado, riscos de oscilações de mercado por ocasião da venda, entre outros. Além disso, os camponeses ficam com uma fatia pequena do valor gerado, e ao longo dos anos vem aumentando sua dependência a financiamentos de políticas públicas, muitos deles repassados pelas próprias fumageiras (ETGES, 2005).

Conforme destacam Boeira e Guivant (2003), a saúde das famílias de camponeses que cultivam o fumo é sistematicamente agredida de diversas formas: pelo uso de agrotóxicos, pelo contato direto com a planta úmida (que libera nicotina, sendo absorvida pela pele) e pelo cheiro das folhas durante a secagem nas estufas. Importa ressaltar que as empresas do tabaco exercem controle sobre todos os processos do cultivo do fumo, sem arcar com quaisquer riscos. Desse modo, os camponeses expõem-se às ameaças decorrentes do cultivo e sujeitam-se às responsabilidades civis, criminais e ambientais, sendo poucos os que têm autonomia sobre as suas práticas (ALMEIDA, 2005).

Frente aos resultados negativos gerados pela modernização da agricultura e da produção de tabaco no âmbito da agricultura camponesa, a abordagem de Ulrich Beck (1995) traz uma compreensão do porquê famílias produtoras implementam iniciativas de diversificação ao tabaco em meio ao discurso de que esta seria uma das atividades mais rentáveis para os camponeses. A priori, se evidencia a diversidade de ações implementadas pelos camponeses que, de acordo com Schneider (2009), não apenas reagem ou se adaptam aos condicionantes externos, mas também são capazes de agir de forma propositiva e autoconfrontar com esta realidade exposta. Segundo o mesmo autor, a chave para compreender as dinâmicas cotidianas dos camponeses está nas inter-relações e interdeterminações que este grupo estabelece com outras esferas, como o Estado, o mercado, as instituições e outros dispositivos coletivos. Todas essas experiências representam formas de resistência, já que na busca por autonomia, constroem-se alternativas possíveis (SCHNEIDER, 2009).

Levando em conta a problemática exposta sobre a cadeia produtiva do tabaco, se torna instigante o fato de, por um lado, o cultivo do tabaco ser considerado uma "boa e praticamente insubstituível" alternativa de renda para o camponês e, por outro, haver famílias que vem realizando atividades de diversificação das suas propriedades para, com isso, terem alternativas de renda e melhor qualidade de vida.

Entendemos inicialmente que essas iniciativas de diversificação são decorrentes da autoconfrontação com a sociedade de risco de Ulrich Beck (1995). No contexto da sociedade de risco, iniciativas em torno da busca por maior autonomia e liberdade a partir de mecanismos que funcionem e operem como alternativas em contexto de privação e dificuldades emergem em contraponto ao modelo vigente, uma autoconfrontação com os riscos produzidos pela própria modernidade, expressa no espaço rural a partir da Revolução Verde. Essas iniciativas são o que Long (2001) conceitua de Perspectiva Orientada ao Ator, cujos conceitos serão trabalhados na seção a seguir. 


\section{A EMERGÊNCIA DA SOCIEDADE DE RISCO: UMA REFLEXÃO SOBRE O MUNDO RURAL "MODERNO" A PARTIR DA PERSPECTIVA ORIENTADA AO ATOR}

Nas ultimas décadas crescem insatisfações diante do modelo tradicional de desenvolvimento, caracterizado pelo crescimento econômico e pela ideia de progresso, aliadas ao reconhecimento acerca do esgotamento dos recursos naturais, à preocupação com o meio ambiente e com diversos problemas sociais. Os problemas que possibilitam o surgimento de uma percepção e representação de risco social são relacionados à preservação de recursos naturais, solo, preservação da biodiversidade das florestas e à produção de alimentos saudáveis. Portanto, estes riscos ambientais percebidos pelos atores sociais têm evidente importância na sociedade moderna denominada sociedade de risco (BECK, 1995). O cultivo do tabaco colabora para a ampliação destes problemas ambientais, pois ao mesmo tempo em que o modelo de produção usa uma quantidade grande de produtos químicos, que contaminam o meio ambiente, utiliza ainda uma quantidade expressiva de lenha que é queimada para o processo de cura. Ambos os processos, altamente poluentes ao meio ambiente e à saúde humana, contribuem para a diminuição da biodiversidade. Além disto, pelo fato do cultivo do tabaco ser realizado em pequenas propriedades, há uma disputa pelas terras agricultáveis com a produção de alimentos.

De acordo com Beck (1995), a sociedade moderna industrial se desenvolveu tão profundamente que produziu mudanças importantes em si mesma. A distinção de si própria originou uma segunda modernidade chamada de modernização reflexiva que, conforme Giddens (1989), não representa somente uma reflexão, mas sim a capacidade da sociedade atual de autoconfrontar-se com o que ela própria produziu, ou seja, com os efeitos colaterais da sociedade industrial, das bases da modernização com as consequências desta modernização.

Giddens (1991) argumenta que a modernidade, associando o crescimento e o progresso à ciência e a racionalização, incorporou conhecimentos técnicocientíficos socialmente construídos para mediar a relação seres humanos e natureza. Tais conhecimentos configuram o que o autor chama de sistemas peritos, que buscaram ao longo da modernidade, instaurar a dimensão do controle e da segurança. Por sistemas peritos entendem-se sistemas de excelência técnica ou competência profissional que organizam grandes áreas dos ambientes material e social em que vivemos hoje. Cabe ressaltar que para os indivíduos em situação de modernidade, a percepção de riscos se dá moldada pela ação dos sistemas peritos (GIDDENS, 1991).

A realidade da modernidade se caracteriza por certo nível de incerteza e até de angústia. Ao mesmo tempo em que a razão humana obtém as informações provenientes dos sistemas peritos, não se possui o domínio pleno das informações no cotidiano. O sistema perito, constituído pelos especialistas, informa à comunidade questões relativas ao conhecimento. A comunidade, ou o indivíduo, de maneira reflexiva, adota ou não o conhecimento transmitido pela comunidade científica, aplicando-a ou não. Isso interfere sobremaneira no cotidiano das pessoas, no resultado dos seus atos e, diretamente, no meio que os envolve. De acordo com a ação reflexiva e diante de determinadas situações da modernidade, ignora-se 0 risco, apesar de estar diante e confiante nos sistemas peritos.

No entanto, o impacto ambiental do industrialismo acabou por afetar a confiança em tais sistemas peritos, originando o que Beck caracteriza como a sociedade de risco (BECK, 2011). Esta marca a passagem da modernização simples para a modernização reflexiva, um estágio no qual a modernização se autodestrói e 
se modifica. "Quanto mais avança a modernização das sociedades modernas, mais ficam dissolvidas, consumidas, modificadas e ameaçadas as bases da sociedade industrial" (BECK, 1995, p. 13).

Para entender as características e as transformações da sociedade atual, a sociedade de alta modernidade, Beck (1995) e Giddens (1991) apresentam a crise ecológica como uma questão fundamental. Esta discussão emerge a partir da década de 1980, com a repercussão de diversos movimentos ambientalistas, bem como autores vinculados atualmente a este debate. Segundo Beck (1995), os efeitos colaterais, como os problemas ambientais, sociais e de saúde humana não são sinônimos de medo ou ameaça, mas configuram-se enquanto riscos. Representam, assim, um perigo que está fortemente associado à dimensão da decisão, caracterizando nossas incertezas cotidianas e rotineiras. Para o autor, os riscos tornam-se a causa e o meio da mudança social, passando a ser o conceito chave a partir do qual é possível interpretar e compreender a vida social.

Outra questão enfatizada como ponto central na argumentação de Beck (1995), que configura uma ruptura entre a sociedade moderna industrial e a sociedade de risco, é a questão da natureza. Não existe nenhum local no planeta onde a natureza não tenha sido internalizada pela ação humana. Um dos elementos centrais dessa análise é a crise ecológica do mundo contemporâneo, em que as restrições quanto ao uso indiscriminado dos recursos naturais está impondo sérias restrições ao desenvolvimento do capitalismo e às consequências dos diferentes processos de industrialização. A natureza tornou-se uma dimensão fundamental da vida social cotidiana: os humanos têm de tomar decisões práticas e ao mesmo tempo de natureza ética (Beck, 1995).

Neste sentido, Abreu (2002, p. 45) contribui no debate salientando que "atualmente, a sensibilidade à noção de risco é fundamental para a cultura moderna, justamente porque, como espécie o homem não tem sua sobrevivência garantida em curto prazo, vivemos diante de incertezas que foram geradas ao longo do tempo pelas próprias ações humanas". Do ponto de vista da existência ou da possibilidade de risco, em alguns momentos a sociedade industrial moderna e a sociedade de risco são semelhantes, pois ambas propiciam péssimas condições de vida e saúde as populações.

No âmbito da agricultura, os perigos tornam-se mais evidentes com a modernização da agricultura. Para Ploeg (2008), a partir dos anos 1960, houve a emergência da agricultura empresarial que se materializou e desenvolveu devido às novas condições introduzidas e consolidadas pelo projeto de modernização massiva no mundo todo, desencadeado pela Revolução Verde. Essas condições são: alta escala de produção, diminuição da absorção do trabalho agrícola, uso de tecnologias dirigidas e intensificadas, produção de monoculturas, processo de mercantilização e reestruturação criando o núcleo de um novo modo de produção agropecuária empresarial.

No âmbito da produção de tabaco, tais problemas também se evidenciam. A partir do sistema de integração, é garantido o uso de todos os insumos necessários, que se configuram enquanto sinônimo de modernidade, mas que carregam riscos para a ecologia e saúde humana. Exemplo disso são os agrotóxicos utilizados no cultivo do tabaco e a exposição à nicotina pela doença da folha verde. Além dos riscos sociais oriundos de vários fatores e da incerteza econômica na qual os fumicultores estão sujeitos.

Beck (1995) atribui peso ao conhecimento social sobre os riscos e a natureza incerta dos mesmos, uma vez que não há por parte da comunidade cientifica ou de peritos, conhecimentos que permitam um controle total dos perigos embutidos nos processos tecnológicos. Nisso, os eventos de insucesso, face ao uso 
de tecnologias modernas, promove a visibilidade dos problemas ambientais e, consequentemente, rupturas nos consensos sociais sobre o progresso. Entendemos que os riscos e os efeitos ecológicos na agricultura são percebidos socialmente, quando os agricultores que fazem uso de tecnologias modernas experimentam eventos de insucesso decorrentes do aparecimento de problemas ambientais (ABREU, 2002).

Neste sentido, entendemos que ao perceberem os riscos aos quais estão sujeitos, os fumicultores procuram realizar iniciativas para minimizar estes riscos. Portanto, a diversificação permite uma maior capacidade para funcionar no meio rural ampliando as possibilidades econômicas, sociais e ambientais e as escolhas que as famílias podem realizar para melhorarem o espaço onde vivem e levarem a vida que desejam. Desta forma, e como aponta Schneider (2010b), quanto mais diversificada for a unidade produtiva, maiores serão as possibilidades de escolha e mais amplas as estratégias que poderão ser estabelecidas para o combate da vulnerabilidade.

Para entender as diferentes formas de atuação e de resposta dos camponeses ao se autoconfrontarem com os efeitos da modernização - nesse caso, expressos pela modernização da agricultura e, consequentemente, pela monocultura do tabaco - faremos uso das contribuições de Long (2001) e Ploeg (2008). Os autores propõem uma abordagem que ressalta a capacidade de agência humana, permitindo que se analisem as práticas, processos e formas de organização empregadas pelos camponeses no sentido de uma mudança social por meio da construção de formas alternativas de garantia de sobrevivência material, e da sua reprodução social como unidades de produção.

Levando em conta essa situação, a Perspectiva Orientada ao Ator (POA) é capaz de possibilitar o entendimento de como os camponeses buscaram a idealização de alternativas para a solução de seus próprios problemas, sendo, um processo social altamente complexo (LONG, 2001). Neste sentido, este autor propõe uma abordagem que ressalta a capacidade de agência humana. Esta permite que se analisem as práticas, processos e formas de organização empregadas pelos camponeses, com vistas a uma mudança social, por meio da construção de formas alternativas de garantia da sobrevivência material, além da sua reprodução social como unidades de produção.

Na POA a noção do ator é afim à noção de agência humana estabelecida por Giddens (1989). Segundo esse autor, a noção de agência humana é resultado de um processo reflexivo dos atores, a partir de sua capacidade de trazer as diferentes situações pela consciência e refletir suas escolhas. Os atores são capazes de compreender o que fazem, porque o fazem, quando o fazem. Esta agência humana é considerada o centro da perspectiva de ator social e é eixo pelo qual giram os planejamentos que tentam reconciliar as noções de estrutura e de ator. A noção de agência, para Long (2007, p. 48) atribui ao ator: "(...) a capacidade de processar a experiência social e desenhar maneiras de lutar com a vida, ainda sob as formas mais extremas de coerção". Dentro dos limites de informação, incertezas e outras restrições (...) os atores sociais tem "capacidade de saber" e "capacidade de atuar".

Nesse sentido, os atores sociais são compreendidos como participantes ativos na construção do desenvolvimento rural, processando informações, colocando em prática suas estratégias em interação com outros atores e instituições, o que Long (2001) conceitua de POA. Assim, o ator é considerado um agente coletivo, que age a partir de processos de interação com outros, e o que define sua condição de ator é sua capacidade de agência. $O$ ator se estabelece 
como um ente coletivo e o que define sua agência é sua "condição de agente", entendida como a capacidade de saber e de agir (GONZALEZ, 2013).

A POA possibilita o entendimento de como os camponeses buscam a idealização de alternativas para a solução de seus próprios problemas, sendo este um processo social altamente complexo (LONG, 2001). Neste sentido, compreende-se que o desenvolvimento ocorre como um processo de mudança social, protagonizado por diversos atores, sendo os camponeses capazes de interpretar a realidade e propor as mudanças necessárias a atender suas necessidades, mobilizando demais atores, instituições e recursos para isso.

Segundo Ploeg (2008), a condição camponesa é caracterizada pela luta por autonomia que se realiza num contexto definido por relações de dependência, marginalização e privações. Essa condição tem como objetivo e se concretiza na criação de uma base de recursos autocontrolada e autogerenciada. Esta, por sua vez, permite formas de coprodução entre o homem e a natureza viva, que interagem com o mercado. Tal coprodução possibilita a sobrevivência, perspectivas de futuro e se realimentam na base de recursos, fortalecendo-a, melhorando o processo de coprodução e fomentando a autonomia. Dessa forma, reduz-se a dependência. Dependendo das particularidades da conjuntura socioeconômica dominante, a sobrevivência e o desenvolvimento de uma base de recursos próprios poderão ser fortalecidos através de outras atividades não agrícolas. Finalmente, existem padrões de cooperação que regulam e fortalecem essas inter-relações. Essa condição se relaciona diretamente com luta por autonomia realizada pelos fumicultores, na busca pela diversificação da propriedade, como pretendemos expressar a seguir:

\section{INICIATIVAS DE DIVERSIFICAÇÃO DAS PROPRIEDADES PRODUTORAS DE TABACO: DA AUTOCONFRONTAÇÃO À CAPACIDADE DE AGÊNCIA}

Nesta seção procuraremos analisar, à luz dos elementos empíricos e teóricos, por que famílias produtoras de tabaco passaram a diversificar a produção. Entendíamos que essas iniciativas seriam respostas aos riscos produzidos pela própria cadeia produtiva do tabaco emergindo a partir do sujeito camponês, a partir de sua realidade, seu modo de vida, seu modo de reprodução social, buscando minimizar estes efeitos. No decorrer da pesquisa, essa hipótese foi se concretizando e encontramos diferentes autoconfrontações aos riscos produzidos pelo cultivo do tabaco, as quais motivaram a busca pela diversificação.

Antes de adentrarmos à exposição do caso empírico, cabe menção à metodologia empregada. Para tal, valemo-nos de um estudo qualitativo, baseado no estudo de caso, qual seja, famílias produtoras de tabaco que diversificam seus meios de vida no município de Santa Cruz do Sul.

A definição do recorte espacial decorreu do fato de o referido município ser o centro da produção de tabaco e das decisões políticas em torno desta cadeia produtiva. Foi um dos primeiros locais de produção no Brasil e onde está instalado o maior pólo nacional de beneficiamento de tabaco do país.

Primeiramente foi realizada uma pesquisa bibliográfica e, posteriormente foram realizadas entrevistas com lideranças de movimentos sociais e entidades que fomentam iniciativas de diversificação. Estas entidades indicaram as famílias fumicultoras que produzem tabaco, mas que, ao mesmo tempo, vem empreendendo ações no sentido de diversificar seus meios de vida.

Desse modo, foram realizadas 4 entrevistas com lideranças de entidades, quais sejam, Movimento dos Pequenos Agricultores (MPA), Escola Família Agrícola (EFA), Centro de Apoio ao Pequeno Agricultor (CAPA) e Empresa de Assistência 
Técnica e Extensão Rural (EMATER), todas envolvidas em iniciativas de diversificação ao tabaco. Estas entidades indicaram 15 famílias que foram entrevistadas. As entrevistas foram degravadas e analisadas à luz dos objetivos da pesquisa.

O instrumento de pesquisa utilizado foi um roteiro com perguntas semiestruturadas, as quais permitem balizar as entrevistas sem, no entanto, encerrar mecanicamente o levantamento de informações. Pelo contrário, proporciona liberdade ao entrevistado e a possibilidade, ao pesquisador, de ser surpreendido pela imprevisibilidade dos diálogos (ANDRADE, 2003). O questionário semiestruturado levantou questões acerca do histórico da família e da propriedade, o que foi produzido, os motivos que levaram a família a diversificar a propriedade, os principais benefícios de produzir tabaco, os principais problemas na produção de tabaco, o modelo de produção integrado, as políticas publicas acessadas.

Dito isso, cabe ressaltar que a evidência do crescimento da consciência social dos riscos decorre da emergência, em escala global, dos problemas ecológicos e da natureza incerta de determinados processos sofisticados do ponto de vista tecnológico. Esta percepção global dos riscos acerca da cadeia produtiva do tabaco gerou discussões no mundo inteiro, pois o hábito de fumar extrapola fronteiras e expõem fumantes e não fumantes aos efeitos nocivos do cigarro no mundo todo.

Esta percepção global dos riscos do tabaco e, os efeitos colaterais do tabagismo, resultaram num tratado internacional, qual seja, a Convenção-Quadro de Controle do Tabaco (CQCT), no qual o Brasil é país signatários e facilitador (FREITAS; RAMBO; SARTORELLI, 2015; SCHNEIDER, 2010-a; SCHNEIDER, 2010-b). Podemos considerar, pautado em Beck (1995) que, no que se refere ao tabagismo, e por consequência, à produção de tabaco, estamos vivendo elementos da segunda fase da sociedade de risco, na qual os perigos da sociedade industrial começam a dominar o debate e os conflitos públicos. Esta fase é decorrente de um processo de conscientização política dos riscos e de implementação de ações para reversão dos mesmos $^{9}$.

Dito isso, cabe chamar atenção para alguns elementos que emergiram ao longo do estudo de caso. $O$ primeiros se refere ao número de integrantes das famílias pesquisadas, que variam de 2 a 5 membros apenas. Outro fator instigante é a ausência de jovens no campo $^{10}$. A maior parte das famílias entrevistadas não apresenta sucessão rural, ou seja, os jovens migraram para a cidade em busca de melhores condições de vida, pois não consideram a produção do tabaco uma atividade a ser seguida. Conforme Abramovay (1998), a migração cidade-campo que afeta a agricultura atualmente, atinge as populações jovens com muito mais ênfase que em momentos anteriores.

\footnotetext{
${ }^{9}$ Reconhecemos que há divergências, sobretudo nos âmbitos locais, inclusive entre famílias camponesas, quanto às externalidades sociais, econômicos e ambientais negativas da cadeia integrada de produção de tabaco. Assim, quando nos referimos à conscientização política dos riscos e de implementação de ações para reversão dos mesmos, estamos nos referindo principalmente à implementação de medidas como a própria CQCT, a Política de Diversificação em Áreas de Tabaco, as ações desenvolvidas por diversos atores sociais como no caso em estudo desenvolvidas pelo MPA, bem como pela EMATER, a EFA e o CAPA. Outrossim, as iniciativas locais e pontuais de diversificação, como as das 15 famílias pesquisadas, denotam a emergência da sociedade de risco.

${ }^{10} \mathrm{Em}$ relação à permanência da juventude no campo, das 15 famílias entrevistadas, 7 possuem jovens de até 29 anos em suas propriedades. Nas outras 8 famílias os jovens já migraram para outras atividades. Há que se ressaltar que destas famílias que os jovens permanecem no campo, a EFA cumpre um papel determinante para esta permanência, pois realiza um trabalho diferenciado na valorização do ser camponês e na participação das famílias no processo de educação.
} 
Como decorrência da migração cidade-campo está o processo de envelhecimento da população e, também, o processo de masculinização do campo, já que as moças estão deixando a zona rural antes e numa proporção maior que os rapazes (ABRAMOVAY et al., 1998). A perspectiva da permanência dos filhos na atividade agrícola depende principalmente das condições internas das famílias, tanto econômicas quanto sociais. Portanto, ao se deparar com as condições geradas com o cultivo do tabaco, com os riscos produzidos, os jovens se deparam com inúmeras contradições e tem maiores dificuldades de adaptação a estes riscos e buscam saídas em outros ramos profissionais.

Ademais, outro fator preocupante se refere à questão da posse da terra. As propriedades são pequenas. Como garantir a sucessão rural em pequenas propriedades? Durante as entrevistas, verificamos que somente duas famílias possuem área maior que um módulo rural, que no município de Santa Cruz do Sul corresponde a 20 hectares. Esse fator também compromete a questão da permanência da juventude no campo. A família 4 reitera que somente quando conseguiu adquirir mais um pedaço de terra que desenvolveu plenamente 0 processo de diversificação, pois "se vai viver somente do fumo a gente não consegue".

As entrevistas evidenciaram ainda que há uma insatisfação diante do moderno sistema integrado de produção de tabaco. Observamos que há uma disseminação da idéia de crescimento econômico através da produção de tabaco e uma associação disto com a ideia de progresso. Mas as entrevistas demonstram que há uma preocupação significativa com a saúde humana e com as consequências para o meio ambiente. O respondente da família 3 comenta que "já tive problemas de saúde na aplicação do veneno e minha esposa não pode colher fumo molhado, nós passamos mal. Esses foram os motivos que resolvi diversificar minha propriedade e depender cada ano menos do fumo".

A figura a seguir busca sistematizar o que apresentamos anteriormente. Como afirmam Giddens (1989) e Beck (1995), a modernização reflexiva não representa somente uma reflexão, mas sim a capacidade da sociedade atual de se autoconfrontar com o que ela própria produziu. No caso analisado, as famílias se defrontam com os efeitos colaterais da modernização da agricultura e do sistema integrado do tabaco e buscam alternativas via diversificação. Torna-se importante ressaltar que os riscos produzidos pela cadeia produtiva em questão são como um sistema, em que um risco leva ou agrava outro.

A dependência à fumageira através do sistema de integração é um mecanismo que subordina o agricultor a aceitar os preços (baixos) estabelecidos pela fumageira. Além disto, estão vulneráveis aos efeitos climáticos como estiagem, granizo, vendavais que prejudicam a produção de tabaco. Ademais são acometidos por diversas intoxicações, seja pelo veneno aplicado no tabaco ou pela própria nicotina presente nas plantas de fumo. Depressão, doença da folha verde, intoxicações são recorrentes em todas as famílias entrevistadas. Outro fator é a penosidade do trabalho com o tabaco, o tempo de realização de uma safra leva mais de um ano. Este é um dos fatores bem expressivos que acentua o processo de migração campo - cidade. 
Figura 1 - Riscos ocasionados pela moderna monocultura do tabaco.

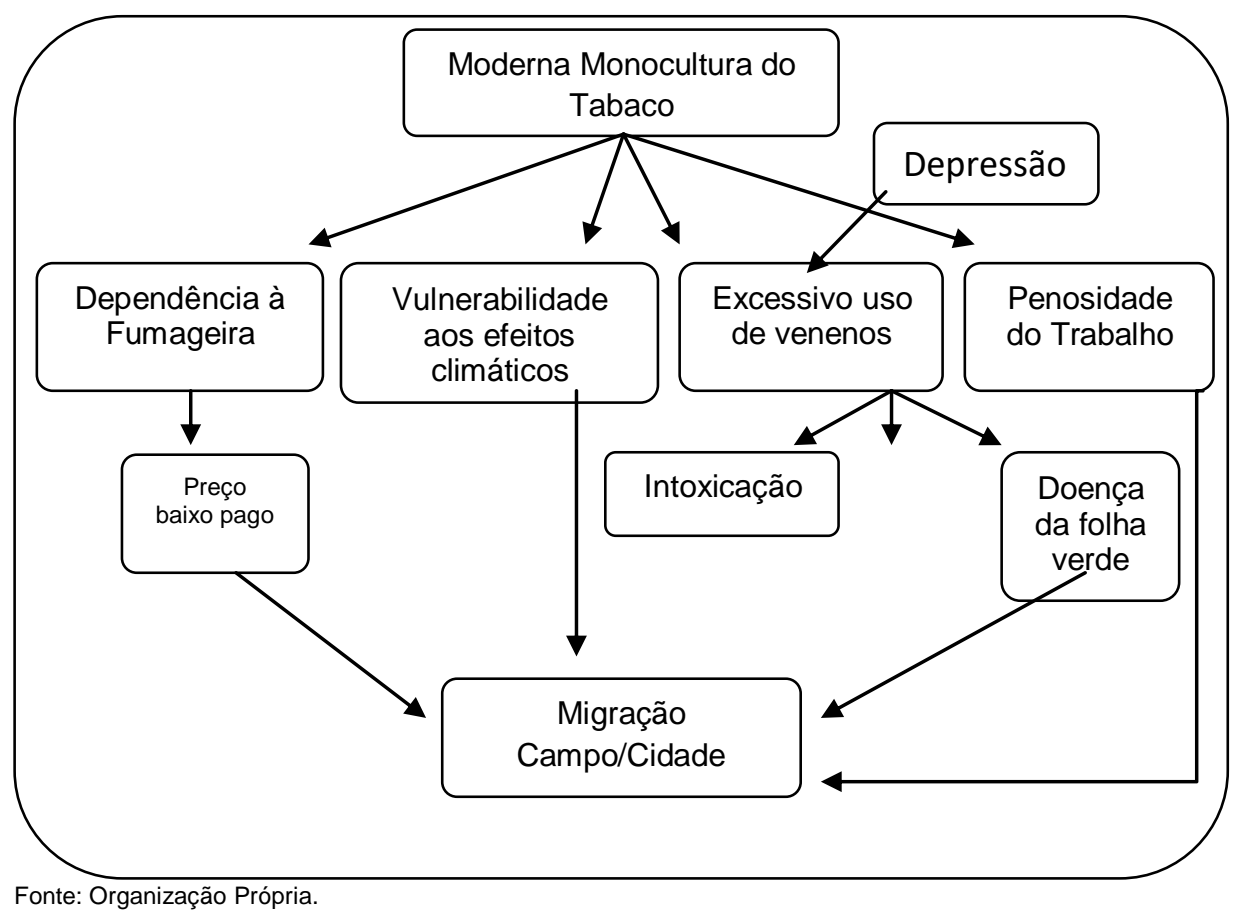

Como demonstraremos a seguir, a pesquisa de campo apontou que a contribuição de Beck (1995) corrobora com a análise de Long (2001), ou seja, as famílias não aguardam simplesmente soluções exógenas, mas são estas que buscam solucionar os problemas gerados pela cadeia produtiva do tabaco. Segundo Long (2001), e tal qual observado nas entrevistas, as famílias percebem riscos e dão diferentes respostas a processos aparentemente homogêneos, representando o que acima denominamos autoconfrontação aos riscos da modernidade.

As famílias entrevistas, analiticamente foram organizadas em cinco grupos: (1) famílias que iniciaram a diversificação por conta própria; (2) famílias que realizaram diversificação com incentivo do MPA; (3) famílias que realizaram diversificação com incentivo da EFA; (4) famílias que realizaram diversificação com incentivo do CAPA; (5) famílias que realizaram diversificação com incentivo da EMATER.

O grupo que iniciou a diversificação por conta própria é composto por três famílias. Nessas famílias, os motivos que levaram a diversificação foram: problema com a comercialização e renda, alto custo de produção, mão de obra e trabalho árduo no tabaco, utilização de muito veneno e intoxicações, doença da folha verde, problemas do clima: chuvas torrenciais, seca, granizo. Nestas famílias, os produtos gerados a partir da diversificação são utilizados para o autoconsumo da família, ou seja, para sua alimentação e dos animais que são fonte de alimentação para a família, mas também para comercialização. Este grupo caracteriza-se por ter pequenas áreas de terra e utilizar destas, uma pequena parte para a produção do 
tabaco. As famílias possuem entre 5 a 15 hectares e realizam o plantio de tabaco em 1,5 a 2,5 hectares.

Foram entrevistadas 5 famílias que realizaram diversificação com incentivo do MPA. Neste grupo, as autoconfrontações encontradas foram as mesmas do grupo anterior. Elas possuem entre 9,7 a 19,8 hectares e destes realizam o plantio de tabaco em 1,5 a 3 hectares. Com o incentivo do MPA acessaram diversas políticas públicas como: Programa Nacional de Fortalecimento da Agricultura Familiar (Pronaf), Programa de Moradia Rural, ATER Agroecologia e Programa Camponês.

O grupo que recebeu incentivo da EFA é composto de 3 famílias. Neste grupo as autoconfrontações se assemelham as do grupo que diversifica por conta própria. Elas possuem de 12 a 40 hectares e destes realizam o plantio de tabaco em 1,5 a 5 hectares. A EFA desenvolve um papel fundamental no sentido de promover a pedagogia da alternância e possibilitar que os jovens estudantes cursem o ensino médio profissionalizante, no qual permanecem uma semana na escola e uma semana nas suas propriedades, desenvolvendo as técnicas que aprenderam numa relação dialética entre teoria/prática.

O CAPA realiza um trabalho de fomento à produção orgânica e venda direta nas feiras. Em Santa Cruz do Sul são mais de 50 famílias apoiadas pelo CAPA, e destas, somente uma ainda produz tabaco. Este fato demonstra que na medida em que as famílias melhoram suas condições de vida, elas abandonam o cultivo do tabaco. A família apresentou as seguintes autoconfrontações: incerteza na comercialização e dependência ao monocultivo do tabaco. Possuem 30 hectares e somente 1 ha é cultivado com tabaco.

As famílias indicadas pela EMATER, em número de três, têm como característica a produção de verduras para comercialização na feira municipal, via PAA e PNAE, além de serem atendidas pela Assistência Técnica e Extensão Rural (ATER) Sustentabilidade. Chama atenção o fato de estas famílias possuírem menores áreas de terra que as demais entrevistadas. Estas áreas variam de 4,5 hectares a 19,5 hectares, e a área ocupada com tabaco variar entre 2 e 5 hectares.

Quanto à diversificação - iniciativas que funcionam e operam como alternativas em contexto de privação e dificuldades - podemos citar: produção de leite, criação de suínos para corte, de galinhas caipiras para corte e ovos, hortaliças, frutíferas, milho, cana de açúcar, feijão, mandioca, batata doce, soja, batatinha, chás, sementes crioulas, peixes, abóbora, moranga, abelhas, etc. Estas atividades, em todas as famílias, são destinadas primeiramente para 0 autoconsumo. Entendemos o próprio autoconsumo como uma estratégia de diversificação, uma vez que as famílias pesquisadas relatam ter tomado a decisão de diversificar diante das privações e riscos do tabaco. Num segundo momento, seis famílias realizam a comercialização na feira do CAPA e na feira livre municipal, duas comercializam via PAA, duas com mercados da região e, cinco famílias vendem diretamente aos consumidores.

Schneider e Gazolla (2007) reforçam que a produção para o autoconsumo tem uma importância significativa para a segurança alimentar e uma alternativa a dependência ao mercado. Se pensarmos no caminho que faz o alimento até chegar à prateleira do supermercado, veremos que a alimentação está desvinculada do "lugar", da identidade e da cultura local, o que Ploeg chamou de "agricultura do não lugar" e ocorre uma padronização dos alimentos no mundo. Isso se reflete na qualidade nutricional dos alimentos (PLOEG, 2008).

Outrossim, uma característica importante encontrada à campo se refere a assistência técnica recebida pelas famílias. Esta tem um papel fundamental no desenvolvimento e deve preparar os camponeses para a necessidade de tomar 
decisões. Portanto, deve focar-se sempre nos efeitos decorrentes da implementação de determinada escolha. Uma decisão dá início a uma mudança. A essa mudança haverá inúmeras reações, algumas positivas, outras negativas. Isso se relaciona diretamente com a análise de Long (2001) na qual a abordagem orientada ao ator que atribui significação à heterogeneidade dos espaços agrários dos camponeses e à importância de considerar como eles próprios moldam os padrões do desenvolvimento agrário. Para Long (2007), a vantagem do trabalho com o enfoque centrado no ator é a possibilidade de perceber diferentes respostas em processos aparentemente homogêneos, ou 0 que acima apresentamos como a autoconfrontação aos efeitos da modernidade.

Nesse sentido, verificou-se uma constante atuação de atores coletivos como MPA, EFA, CAPA e EMATER que auxiliam nos processos de diversificação das famílias. A ação destes movimentos sociais e entidades podem ser consideradas, como capacidade de agência. Esta não é simplesmente um atributo do ator individual. Ela se manifesta quando ações particulares causam uma mudança em relação a um estado de coisas ou curso de eventos preexistente. Por conseguinte, a agência requer capacidade de organização e não é simplesmente o resultado de certas capacidades cognitivas, poderes persuasivos ou formas de carisma que um indivíduo possa ter. A agência depende da emergência de uma rede de atores que se envolvem nos projetos e práticas de outro indivíduo (PLOEG, 2008).

Cabe mencionar ainda que a capacidade de agência facilita o acesso à políticas públicas. As famílias tiveram acesso a várias políticas públicas que foram extremamente importantes no processo de diversificação. É o caso do Pronaf que financiou diversas estruturas produtivas, do programa de Moradia Rural Minha Casa Minha Vida que proporcionou morar com mais dignidade, dos canais institucionais de comercialização (PAA, PNAE), da ATER Agroecologia e Sustentabilidade, que fomentaram a produção de alimentos saudáveis, e recentemente do Programa Camponês, um programa estadual de fomento a recuperação de solo e estruturas de produção.

Por sua vez, cabe enfatizar que, apesar de apresentarem características de diversificação produtiva e pluriatividade, os agricultores entrevistados ainda possuem no fumo, sua principal fonte de renda. Entretanto, as demais atividades realizadas têm um papel imprescindível no fornecimento de alimentos para a família, bem como garantia da soberania alimentar. Além disto, essa produção de alimentos está vinculada a uma preocupação com a saúde das famílias, pois das 15 entrevistadas, 12 estão em transição para agroecologia, uma tem certificado de produção orgânica e apenas duas tem produção convencional. Ou seja, as iniciativas de diversificação que vem sendo mobilizadas pelas famílias, operam como alternativas ao contexto de privação e dificuldades da cadeia do tabaco, na medida em que vem diminuindo sua subordinação ao sistema de integração e vem empregando práticas agrícolas mais sustentáveis por meio da produção orgânica e agroecológica. Pode-se afirmar ser esta a principal diferença da proposta de diversificação sugerida pela indústria fumageira em relação a quem vem sendo empregada pelas entidades estudadas. A diversificação promovida por estas, se relaciona diretamente com a autonomia das famílias, com a utilização dos recursos existentes na propriedade. A proposta daquelas, se baseia na utilização do pacote agroquímico fornecido pelas fumageiras e reutilizado na diversificação.

Enquanto limitantes à diversificação, o estudo demonstrou que a organização da cadeia produtiva do tabaco talvez seja o mais significativo. Enquanto o fumo tem comércio garantido, entrega de insumos e busca da produção na propriedade, a produção de alimentos demanda a construção e estruturação de todo 
o processo. Embora estejam sendo construídos canais de comercialização - em geral promovendo circuitos curtos agroalimentares - toda esta comercialização depende da capacidade de agência do camponês. Além de organizar a produção e buscar todas as informações para isso, este precisa buscar construir e fortalecer o mercado, construindo relações de confiança com o consumidor. Precisa organizar a produção, pensar na logística, pensar na estrutura de transporte, no custo deste processo, na legislação sanitária, na certificação dos produtos orgânicos e agroecológicos. Este é um grande desafio que as ações de diversificação em áreas de tabaco necessitarão enfrentar. Ainda não há um circuito agroalimentar com o mesmo aparato e organização da indústria fumageira, com a garantia de mercado que o sistema integrado de tabaco apresenta. Nesse sentido, a política de ATER é uma ferramenta fundamental no auxílio a esta organização.

Este estudo apontou ainda para a necessidade de avanços nos processos de diversificação. As famílias entrevistadas ampliaram sua produção para o autoconsumo e se inseriram em novos mercados. Entretanto, o tabaco ainda é sua principal fonte de renda. Assim, é preciso ir além para fortalecer a autonomia das famílias e reduzir a exposição aos riscos gerados pelo sistema de integração do tabaco. Fica evidente a necessidade de ampliar as políticas públicas para incentivar a comercialização da produção, pois as que existem são insuficientes. A complexidade no processo da comercialização, a burocracia e gestão, a organização da logística, as leis sanitárias são algumas das barreiras que precisam ser superadas para que os camponeses possam realizar plenamente o processo de diversificação.

\section{CONSIDERAÇÕES FINAIS}

Levando em conta a problemática exposta sobre a cadeia produtiva do tabaco, se torna instigante o fato de, por um lado, o cultivo do tabaco ser considerado uma "boa e praticamente insubstituível" alternativa de renda para o camponês e, por outro, haver muitas famílias que vem realizando atividades de diversificação em suas propriedades. Entendemos que essas iniciativas de diversificação são decorrentes da autoconfrontação com a sociedade de risco como aborda Ulrich Beck (1995). No contexto da sociedade de risco, iniciativas em busca de maior autonomia e liberdade frente ao modelo de agricultura preconizado pela Revolução Verde emergem em contraponto à homogeneidade deste modelo. Essas iniciativas são o que Long (2007) conceitua de Perspectiva Orientada ao Ator. Essa abordagem ressalta a capacidade dos atores desenvolverem iniciativas de diversificação, no sentido de buscar alternativa à produção hegemônica do tabaco. Isso implica levar em conta a realidade local, vinculada à cultura, ao modo de ser e de viver camponês, fortalecendo sua capacidade de agência na condução e promoção do desenvolvimento, num processo marcado por diversas formas de resistência e busca por autonomia.

Long (2001) considera que os diferentes atores sociais não são destinatários passivos de intervenções, mas sim participantes ativos, com capacidade de criar estratégias através de suas interações sociais e institucionais. Consideramos que os camponeses, foco desta pesquisa, estão sendo capazes de criar estratégias que vem aumentando - mesmo que ainda de forma incipiente e pontual - sua autonomia e liberdade, criando alternativas num contexto de privação e dificuldade decorrente do sistema de integração da cadeia produtiva do tabaco.

A realidade paradoxal em que vivem as famílias pesquisadas remete a uma busca incansável por melhorias na qualidade de vida, bem como, numa preocupação constante em garantir sua reprodução social. Os mecanismos que 
levam as famílias produtoras de tabaco a implementarem iniciativas de diversificação decorrem da autoconfrontação aos riscos gerados pela produção de tabaco: a diminuição da mão de obra no campo, resultante da migração campocidade, na busca por melhores condições de vida, acentuada pelo fato de o tabaco ser um cultivo exigente em mão de obra. $O$ alto custo de produção do cultivo do tabaco que é dependente de insumos externos da propriedade e fornecidos a priori pelas fumageiras, o que resulta no endividamento prévio das famílias. A dificuldade na comercialização, pois os fumicultores tem pouca autonomia na classificação e na venda do tabaco, realizadas nas dependências da fumageira. $O$ fato das propriedades serem pequenas, dificulta a produção de outros cultivos. A falta de comércio garantido para a venda da produção de alimentos dificulta o avanço nos processos de diversificação. $\mathrm{E}$ por último, e não menos importante, a questão cultural e histórica da região que, ao longo dos anos, teve seu desenvolvimento pautado na produção do tabaco.

Ao observarmos a dinâmica das mudanças promovidas pelas famílias produtoras de tabaco, verificou-se que passaram a fomentar diversas atividades, ou seja, a diversificar. Para tanto, verificamos o papel imprescindível da capacidade de agência, seja dos camponeses, seja das entidades que Ihes apóiam. Segundo Schneider (2009), a chave para compreender as dinâmicas cotidianas dos camponeses está nas inter-relações e interdeterminações que este grupo estabelece com outras esferas, como o Estado, o mercado, as instituições e outros dispositivos coletivos. Essas experiências representam formas de resistência, já que na busca por autonomia, constroem-se alternativas possíveis (SCHNEIDER, 2009).

À luz da pesquisa de campo, para além da atuação individual dos atores sociais, também é relevante sua interação em grupos coletivos, como no caso do MPA, EFA, CAPA, EMATER, que auxiliaram nos processos de diversificação das famílias. A ação destes movimentos sociais e entidades pode ser considerada como uma capacidade de agência. Esta por sua vez, não é simplesmente um atributo do ator individual. Ela manifesta-se quando ações particulares causam uma mudança em relação a um estado de coisas ou curso de eventos preexistente, acarreta relações sociais e somente pode se tornar efetiva através delas.

As entidades citadas mediaram políticas públicas acessadas pelas famílias fumicultoras, quais sejam: o Programa Nacional de Fortalecimento a Agricultura Familiar (Pronaf), Programa de Moradia Rural Minha Casa Minha Vida, Assistência Técnica e Extensão Rural (ATER). Ademais, estão acontecendo ações, de ATER, desenvolvidas pelas entidades, o que vem promovendo circuitos curtos agroalimentares.

Assim, ao analisar os mecanismos que levam famílias produtoras de tabaco a implementarem iniciativas de diversificação e a dinâmica destas mudanças dentre as famílias, este estudo acabou apontando que há uma necessidade de avançar nos processos de diversificação para fortalecer a autonomia e liberdade das famílias. Grande parte das famílias apresenta uma considerável diversificação produtiva, mas demanda avançar na diversificação de renda. Fica clara a necessidade de ampliar as políticas públicas de incentivo a comercialização da produção, pois as que existem ainda parecem incipientes, dada a realidade das famílias pesquisadas. A complexidade no processo da comercialização, a burocracia e gestão, a organização da logística, as leis sanitárias são algumas das barreiras que precisam ser superadas para que os camponeses possam realizar plenamente o processo de diversificação.

Por fim, entendemos que as iniciativas de diversificação ao cultivo do tabaco surgem como resultado da autoconfrontação aos riscos gerados pela modernização da agricultura em geral, e em específico, da monocultura do tabaco. 
Ademais, essas iniciativas de diversificação são possíveis pela capacidade de agência dos próprios atores sociais envolvidos, sejam eles atores individuais ou coletivos e pelo acesso a políticas públicas. Pode-se considerar que os camponeses ao se autoconfrontar, tanto com os efeitos colaterais do moderno sistema integrado de produção de tabaco, quanto com os riscos sistêmicos decorrentes na questão ambiental, social e econômica, implementam iniciativas distintas para ampliar as fontes de renda e reduzir a dependência de fatores externos.

\section{REFERÊNCIAS}

ABRAMOVAY, R.; SILVESTRO, M. L.; CORTINA, N.; BALDISSERA, I. T.; FERRARI, D. L.; TESTA, V. M. Juventude e agricultura familiar: desafios dos novos padrões sucessórios. Brasília: UNESCO, 1998.

ABREU, L. S. A construção social da relação com o meio ambiente: análise das percepções e representações sociais de risco ecológico em um município da Mata Atlântica Brasileira. 2002. In Tese de Doutorado do Departamento de Antropologia do Instituto de Filosofia e Ciências Humanas. Universidade de Campinas.

AFUBRA. Famílias fumicultoras: aspectos socioeconômicos. Disponível em: http://www.afubra.com.br. Acesso em: jul. de 2014.

ALMEIDA, G. E. G. Fumo: servidão moderna e violação de direitos humanos. Curitiba: Terra de Direitos, 2005, p.168.

ANDRADE, R. A. Introdução à metodologia do trabalho científico. 6 ed., São Paulo: Atlas, 2003.

ANUÁRIO BRASILEIRO DO TABACO. Santa Cruz do Sul: Editora Gazeta Santa Cruz, 2014. p. 128.

BECK, U.; GIDDENS, A.; LASH, S.(Orgs.) Modernização reflexiva. São Paulo: Ed. da UNESP, 1995.

BECK, U. Sociedade de risco: Rumo a uma outra modernidade. São Paulo, editora 34, 2. ed., 2011.

BOEIRA, S. L.; GUIVANT, J. S. Indústria de tabaco, tabagismo e meio ambiente: as redes ante os riscos. Cadernos de Ciência e Tecnologia. Brasília, v. 20, n. 1, p. 45-78, jan./abr. 2003.

CARVALHO, H. M. O campesinato contemporâneo como modo de produção e como classe social. Curitiba, março de 2012.

DELGADO, G. C. Do capital financeiro na agricultura à economia do agronegócio: mudanças cíclicas em meio século (1965-2012). Porto Alegre, editora da UFRGS, 2012.

DESER. A cadeia produtiva do fumo. Revista Contexto Rural. Ano III, n. 04; Curitiba, 2003. 
DESER. Tabaco: da produção ao consumo, uma cadeia da dependência. Revista. Curitiba, 2010.

ETGES, V. Desenvolvimento regional sustentável: o território como paradigma. REDES, Santa Cruz do Sul, v. 10, 2005.

FREITAS, T. D. A diversificação dos meios de vida como expansão das capacitações: por uma sociologia das condições de vida na fumicultura no Rio Grande do Sul. 2015. 326 p. Tese (Doutorado em Sociologia) - Universidade Federal do Rio Grande do Sul, Curso de Pós Graduação em Sociologia, Porto Alegre, 2015.

FREITAS, T. D.; RAMBO, A. G.; SARTORELLI, A. Os meios e as condições de vida no espaço rural: o caso das famílias produtoras de tabaco em Arroio do Tigre (RS) e Laranjeiras do Sul (PR). Redes (St. Cruz Sul, Online), v. 20, n. 3 - Suplemento, p. 138 - 162, set./dez. 2015.

GAZOLLA, M. SCHNEIDER, S. A produção da autonomia: os "papéis" do autoconsumo na reprodução social dos agricultores familiares. Estud.soc.agric, Rio de Janeiro, v. 15, n. 1, 2007, 89-122.

GIDDENS, A. A construção da sociedade. São Paulo: Martins Fontes, 1989.

As consequências da modernidade. São Paulo: Editora da Universidade Estadual Paulista, 1991.

GONZALEZ, S. R.; PEREIRA, V. C.; DAL SOGLIO, F. K. A perspectiva orientada ao ator em estudos sobre Desenvolvimento Rural. Perspectivas Rurales. Nueva época, Año 13, n. 25.

GORGEN, S. A. Os novos desafios da agricultura camponesa. Porto Alegre: Editora Vozes, 2004.

LONG, N. Development sociology: actor perspectives. London and New York: RoutledgeTaylor\&Francis Group. 2001. p. 285.

Sociología Del desarrollo: una perspectiva centrada en el actor. México, Centro de Investigaciones y Estudios Superiores em Antropología Social: El Colegio de San Luis. 2007, p. 504.

PINHEIRO, S.; LUZ, D. Ladrões de natureza: uma reflexão sobre a biotecnologia e o futuro do planeta. Porto Alegre: Fundação Juquira-Candiru, 1998.

PLOEG, J. D. V. Camponeses e impérios alimentares. Porto Alegre, UFRGS, 2008.

SARTORELLI, A. RAMBO, A. G. Os meios e as condições de vida dos agricultores familiares produtores de tabaco - um estudo no município de Laranjeiras do Sul/PR. Extensão Rural, Santa Maria, v. 21, n. 4, out./dez, p.131-173, 2014. Disponível em: $<$ https://periodicos.ufsm.br/extensaorural/article/view/10801>. Acesso em: 20 nov. 2016. 
SCHNEIDER, S. Reflexões sobre diversidade e diversificação agricultura, formas familiares e desenvolvimento rural. Rurais, v. 4, n. 1, p. 81-131, março/2010.

Agricultura Familiar e pluriatividade. In: A pluriatividade na agricultura familiar. Porto Alegre: Editora da UFRGS, 2009.

Diversificação como estratégia de desenvolvimento rural: referências teóricas para construção de alternativas economicamente sustentáveis de diversificação da produção e renda em áreas de cultivo do tabaco no Brasil subsídios à implementação dos Artigos 17 e 18 da Convenção-Quadro para Controle do Tabaco. Porto Alegre, 2010a. (Relatório).

Subsídios técnicos ao grupo de trabalho para a complementação dos artigos 17 e 18 da Convenção Quadro para o Controle do Tabaco. Porto Alegre, 2010b. (Relatório).

Referências para a elaboração de uma matriz (template) de análise da diversificação da produção em áreas cultivadas com tabaco no Brasil. Porto Alegre, 2012. (Relatório).

ZAMBERLAN, J. Agroecologia: caminho de preservação do agricultor e do meio ambiente. Petrópolis, RJ: Vozes, 2012. 